\title{
Influence of anaesthetic agents on contractions of the pregnant rat myometrium in vivo.
}

Kimizuka M., Tokinaga Y., Kazuma S., Azumaguchi R., Hamada K., Yamakage M. Sapporo Medical University, Dept of Anaesthesiology, Hokkaido, Japan

\section{Background:}

* Propofol is used after extraction of the fetus in pregnant women who have received combined spinal-epidural anaesthesia for caesarean section. In previous studies, it was shown that propofol has an inhibitory effect on uterine contraction like volatile anesthesia1,2).

* On the other hand, it has been shown that dexmedetomidine is an a2-adrenergic agonist that induced uterine contraction via a pathway involving G protein ${ }^{3)}$.

* However, there are no data on a comparison of the effects of propofol, sevoflurane and dexmedetomidine on contractions of a pregnant rat myometrium in vivo .

* The aim of this study was to determine the effects of anaesthetic agents on contractions of the pregnant rat myometrium.

REFERENCES

1) Anesthesiology $2001 ; 95: 1245-55$

2) Acta Anaesthesiol Scand 2005;49:1355-1359

Methods:

3) European Journal of pharmacology 2000;390:185-195

* With institutional approval, pregnant rats were anaesthetized and fetuses were removed. A balloon was inserted into the uterus to measure contractions of the myometrium (figure 1, 2).

* Uterus muscular contractions of the pregnant rats that were sedated with propofol $(30 \mathrm{mg} /$ $\mathrm{kg} / \mathrm{hr}, 150 \mathrm{mg} / \mathrm{kg} / \mathrm{hr})$, dexmedetomidine $(6 \mathrm{mcg} / \mathrm{kg} / \mathrm{hr}$, $30 \mathrm{mcg} / \mathrm{kg} / \mathrm{hr}$ ) or sevoflurane $(2 \%, 5 \%)$ were measured.

* Statistical analysis was performed using the unpaired $t$ test. $\mathrm{P}$ values $<0.05$ were considered statistically significant.

\section{Results:}

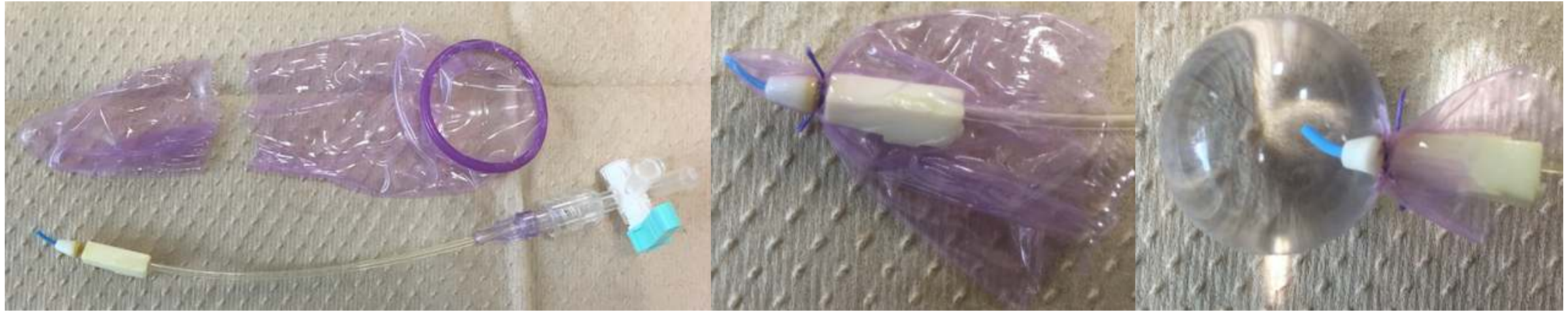

Figure 1. A balloon to measure contractions of the myometrium.
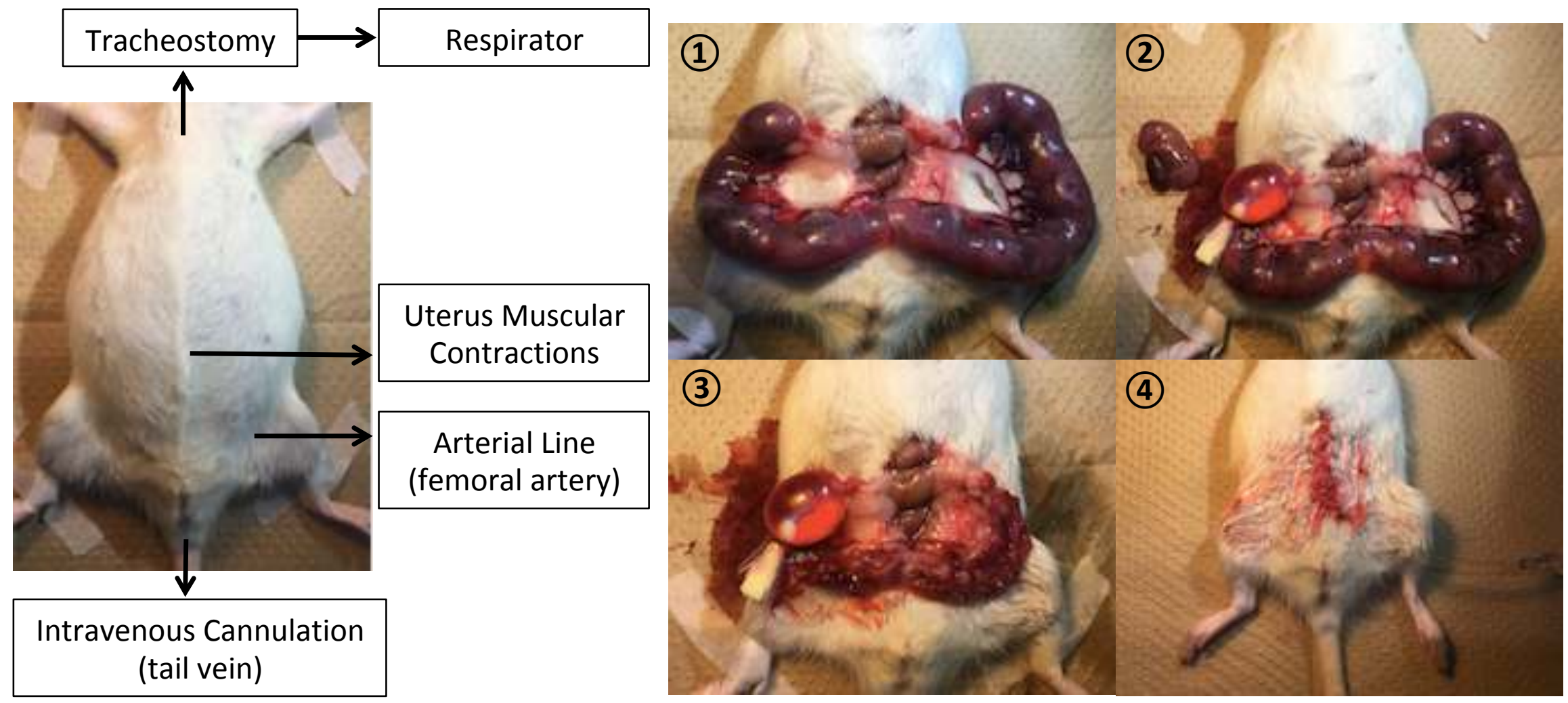

Figure 2. Diagram and balloon insertion.

* Dexmedetomidine significantly augmented contractions of the pregnant rat myometrium. However, there were not significant difference in myometrium contractions in rats sedated with propofol or sevoflurane (figure 3).

* The effects of every anaesthetic agents on contraction-frequency did not change significantly.

\section{Conclusions:}

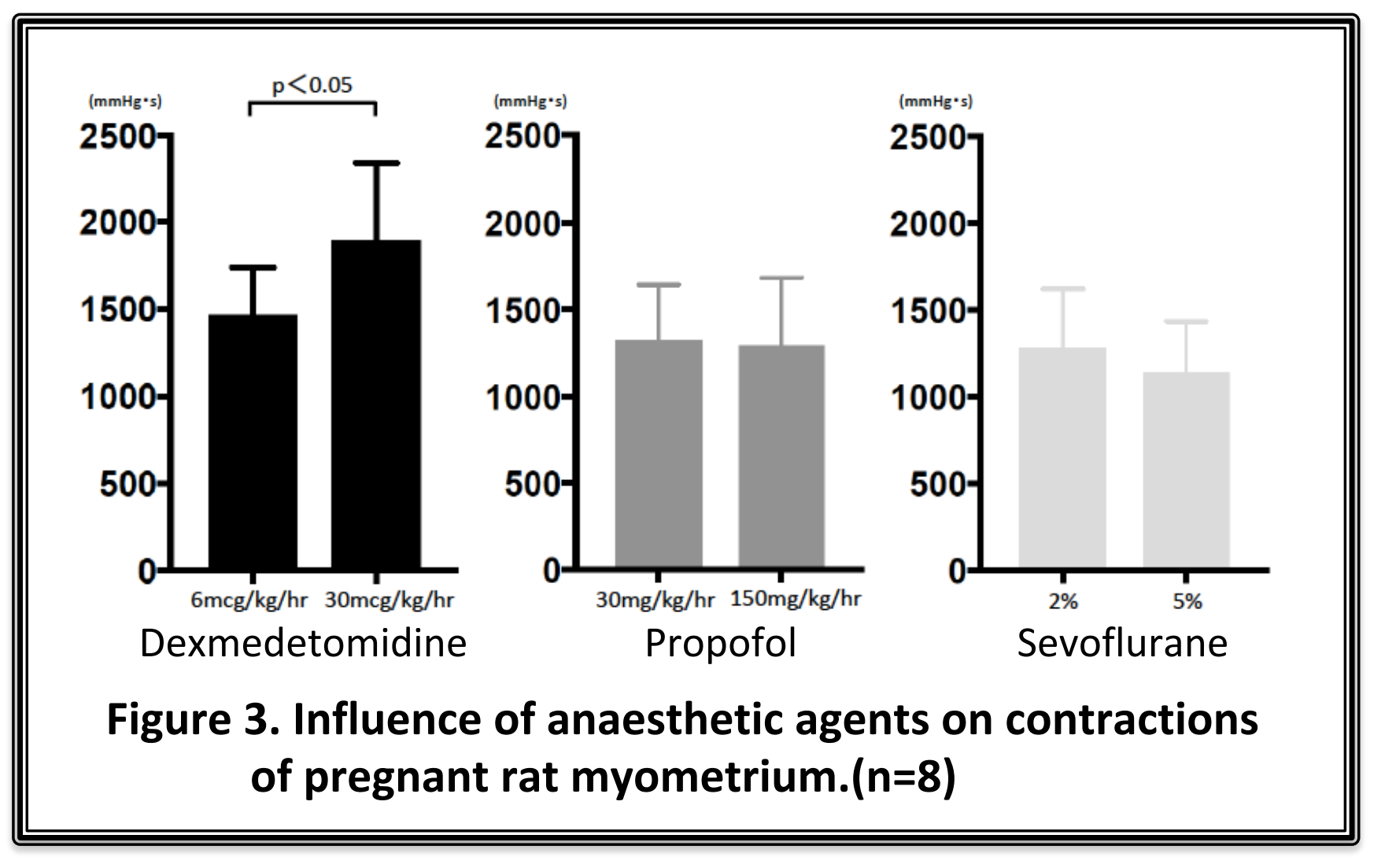

Dexmedetomidine significantly augmented contractions of the pregnant rat myometrium.

* Dexmedetomidine may be preferable for maintaining uterine contraction in caesarean section. 